\title{
Nitric Oxide May Mediate the Hemodynamic Effects of Recombinant Growth Hormone in Patients with Acquired Growth Hormone Deficiency
}

\author{
A Double-blind, Placebo-controlled Study
}

\author{
Rainer H. Böger, ${ }^{\star}$ Cord Skamira, ${ }^{\ddagger}$ Stefanie M. Bode-Böger, ${ }^{\star}$ Georg Brabant, ${ }^{\ddagger}$ Alexander von zur Mühlen, ${ }^{\ddagger}$ \\ and Jürgen C. Frölich* \\ *Institute of Clinical Pharmacology, and ${ }^{\ddagger}$ Department of Endocrinology, Hannover Medical School, 30625 Hannover, Germany
}

\begin{abstract}
We studied the effects of recombinant growth hormone on systemic nitric oxide (NO) formation and hemodynamics in a double-blind, placebo-controlled trial in adult patients with acquired growth hormone deficiency. 30 patients were randomly allocated to either recombinant human growth hormone (r-hGH; $2.0 \mathrm{IU} / \mathrm{d})$ or placebo for $12 \mathrm{mo}$. In the subsequent $12 \mathrm{mo}$, the study was continued with both groups of patients receiving $\mathrm{r}-\mathrm{hGH}$.

In months $1,3,6,9$, and 12 of each year, urine and plasma samples were collected for the determination of urinary nitrate and cyclic GMP as indices of systemic NO production, and of plasma IGF-1 levels. Cardiac output was measured in months 1,12 , and 24 by echocardiography.

r-hGH induced a fourfold increase in plasma IGF-1 concentrations within the first month of treatment. Urinary nitrate and cyclic GMP excretion rates were low at baseline in growth hormone-deficient patients (nitrate, 96.8 $\pm 7.4 \mu \mathrm{mol} /$ mmol creatinine; cyclic GMP, $63.6 \pm 7.1 \mathrm{nmol} / \mathrm{mmol}$ creatinine) as compared with healthy controls (nitrate, $167.3 \pm 7.5$ $\mu \mathrm{mol} / \mathrm{mmol}$ creatinine; cyclic GMP, $155.2 \pm 6.9 \mathrm{nmol} / \mathrm{mmol}$ creatinine). These indices of NO production were significantly increased by r-hGH, within the first 12 mo in the GH group, and within the second $\mathbf{1 2} \mathrm{mo}$ in the placebo group. While systolic and diastolic blood pressure were not significantly altered by r-hGH, cardiac output significantly increased by $30-40 \%$, and total peripheral resistance decreased by $\sim 30 \%$ in both groups when they were assigned to $\mathrm{r}-\mathrm{hGH}$ treatment. In the second study year, when both groups were given r-hGH, there were no significant differences in plasma IGF-1, urinary nitrate, or cyclic GMP excretion, or hemodynamic parameters between both groups.

In conclusion, systemic NO formation is decreased in untreated growth hormone-deficient patients. Treatment with recombinant human growth hormone normalizes urinary ni-
\end{abstract}

Address reprint requests to Rainer H. Böger, Institute of Clinical Pharmacology, Hannover Medical School, Konstanty-Gutschow-Str. 8, 30625 Hannover, Germany. Phone: 49-511-532-4631; FAX: 49-511532-5199.

Address correspondence to Rainer H. Böger, Falk Cardiovascular Research Center, Stanford University School of Medicine, Stanford, CA 94305-5246. FAX: 415-725-1599.

Received for publication 9 July 1996 and accepted in revised form 4 October 1996.

J. Clin. Invest.

(C) The American Society for Clinical Investigation, Inc. 0021-9738/96/12/2706/08 \$2.00

Volume 98, Number 12, December 1996, 2706-2713 trate and cyclic GMP excretion, possibly via IGF-1 stimulation of endothelial NO formation, and concomitantly decreases peripheral arterial resistance. Increased NO formation may be one reason for improved cardiovascular performance of patients with acquired hypopituitarism during growth hormone therapy. (J. Clin. Invest. 1996. 98:2706-2713.) Key words: insulin-like growth factor-1 $\bullet$ cyclic guanidine monophosphate $\cdot$ endothelium $\bullet$ echocardiography $\bullet$ gas chromatography-mass spectrometry

\section{Introduction}

Replacement therapy with corticosteroids, thyroid hormones, and sex hormones has long been used for the treatment of hypopituitarism, but morbidity and mortality of these patients have remained high. This is mainly due to increased risk of cardiovascular disease associated with growth hormone deficiency (1). Growth hormone-deficient patients have a 1.9-fold higher risk of death from cardiovascular disease than agematched controls (1). However, the relationship between growth hormone deficiency and cardiovascular disease has remained unclear. Data suggest that growth hormone-deficient patients often have high serum cholesterol and/or triglyceride concentrations $(2,3)$ and low HDL cholesterol levels (4). Growth hormone treatment reduces plasma cholesterol concentrations (5). Increased body fat and high body mass index in growth hormone-deficient patients may also increase the risk of cardiovascular disease $(4,6,7)$.

Other as yet not fully appreciated cardiovascular effects of growth hormone may also be involved: growth hormone administration increases heart rate and cardiac output in healthy subjects (8), which may point to a decreased peripheral resistance. Indeed, decreased total peripheral resistance has been shown after 26 wk of growth hormone administration in 10 patients with growth hormone deficiency (9). Accordingly, hypertension is frequent among growth hormone-deficient patients (4).

Most of the physiological effects of growth hormone on the heart and cardiovascular system appear to be mediated by local production of insulin-like growth factor-1 (10-12), and the serum concentrations of IGF-1 have been used to measure growth hormone release by the pituitary gland (13). Endothelial cells possess high affinity binding sites for IGF-1 (14). Wu et al. (15) were the first to demonstrate that the vascular effects of IGF-1 are endothelium dependent. Haylor et al. (16) further specified these observations by showing that the hemodynamic effects of IGF-1 in isolated perfused kidneys are dependent upon the release of nitric oxide $(\mathrm{NO})^{1}$ from the endo-

1. Abbreviations used in this paper: $\mathrm{NO}$, nitric oxide; $\mathrm{r}-\mathrm{hGH}$, recombinant human growth hormone. 
thelium. Moreover, a direct NO releasing effect of IGF-1 has recently been shown in cultured human endothelial cells (17).

Nitric oxide, which is synthesized in endothelial cells from the amino acid precursor L-arginine (18), has been identified as a paracrine mediator of vasodilatation, inhibition of platelet aggregation and leukocyte adhesion, and inhibition of smooth muscle cell growth (19). Decreased biological activity of NO has been shown to be associated with atherosclerosis and hypertension $(20,21)$, and restoration of the biological activity of NO induces antiatherosclerotic effects in animal models of hypercholesterolemia:atherosclerosis $(20,22,23)$. The endogenous formation rate of $\mathrm{NO}$ can be assessed by quantifying the urinary excretion of its final metabolite, $\mathrm{NO}_{3}{ }^{-}$, and of its second messenger, cyclic GMP (20, 24-26).

In the present study, we investigated in a double-blind, placebo-controlled manner whether systemic NO formation is increased in growth hormone-deficient adults during replacement therapy with recombinant human growth hormone.

\section{Methods}

Patients and study design. 41 adult patients with acquired hypopituitarism were screened for the presence of growth hormone deficiency. Patients were selected if growth hormone deficiency acquired in adulthood had been diagnosed at least $1 \mathrm{yr}$ before inclusion into this study, but not already treated with growth hormone. Further inclusion criteria were stable conventional pituitary hormonal replacement therapy and no major concomitant illnesses or malignancies. The presence of recurrent hypophyseal tumor was excluded by cranial computer tomography and/or nuclear resonance imaging. Further exclusion criteria were previous acromegaly, previous treatment with growth hormone, any concomitant serious chronic disease, diabetes mellitus, manifest hypertension, pregnancy, or medication interfering with recombinant human growth hormone (r-hGH) effects. Patients were screened for the presence of growth hormone deficiency (growth hormone response $<2 \mathrm{ng} / \mathrm{ml}$ in hypoglycemic growth hormone stimulation test) and correspondingly low IGF-1 levels $(<5$ th percentile for age and sex, reference 27) at the beginning of the study. A medical history and a thorough physical examination were performed at this time.

Of the 41 patients screened, 11 had to be excluded for the following reasons: plasma IGF- 1 not $<5$ th percentile for age and sex, $n=1$; recurrent hypophyseal tumor, $n=4$; concomitant serious chronic diseases, $n=3$; hypertension, $n=1$; no informed consent given, $n=2$.
The remaining 30 patients (mean age, $41.5 \pm 2.0 \mathrm{yr}$; height, $168.4 \pm 1.9 \mathrm{~cm}$; weight, $77.1 \pm 2.9 \mathrm{~kg}$ ) with acquired hypopituitarism were included in this study after they had given their informed written consent. The diagnoses and clinical characteristics of these patients at baseline are given in Table I. The study protocol had previously been approved by the Institutional Ethics Committee for Studies in Humans at Hannover Medical School. Patients were invited to the outpatient clinic for a baseline investigation (month 0 ). Baseline measurements of systemic NO production assessed at this time were compared with data from 30 age- and sex-matched, healthy controls (control group; mean age, $42.0 \pm 2.0 \mathrm{yr}$ ).

The study consisted of two phases: during the first $12 \mathrm{mo}$, patients were randomly allocated to treatment with $2.0 \mathrm{IU} / \mathrm{m}^{2}$ body surface per d of recombinant human growth hormone ( $\mathrm{r}-\mathrm{hGH}$; Novo Nordisk, Denmark) (GH group), or the corresponding volume of placebo (placebo group), given as a subcutaneous injection using the Nordiject 24 pen injector at 2200 hours, in a double-blind design. During the second 12-mo, patients in the $\mathrm{GH}$ and placebo groups were treated with r-hGH in an open study design. At the beginning of the double-blind study phase, all patients underwent a dose-escalation procedure with $0.5 \mathrm{IU} \mathrm{r}-\mathrm{hGH} / \mathrm{m}^{2}$ per $\mathrm{d}$ in weeks $0-2,1.0 \mathrm{IU} / \mathrm{m}^{2}$ per $\mathrm{d}$ in weeks $3-6$, and $2.0 \mathrm{IU} / \mathrm{m}^{2}$ per d starting in week 7 , or the correspondingly escalating injection volumes of placebo. At the beginning of the open study phase, all patients (previous placebo group as well as previous $\mathrm{GH}$ group) underwent the same dose escalation procedure with $\mathrm{r}-\mathrm{hGH}$ as described above to protect the randomization code. Patients developing persistent symptoms compatible with r-hGH side effects (e.g., oedema, arthralgia, hypertension) were subjected to a single-step dose reduction to $1.0 \mathrm{IU} / \mathrm{m}^{2}$ per $\mathrm{d}$. In the case of nonremission of symptoms at $1.0 \mathrm{IU} / \mathrm{m}^{2}$ per day the patient was withdrawn from the study. All concomitant medication remained unchanged during the whole study period.

Follow-up investigations were performed at months 1, 3, 6, 9, and 12 , and at month $13,15,18,21$, and 24 . At each investigation, blood pressure and heart rate were recorded after the patients had remained in the supine position for at least $30 \mathrm{~min}$. A venous plasma sample was drawn for the determination of plasma IGF-1 concentration, and a urine sample was collected for the determination of urinary nitrate and cyclic GMP excretion rates. Plasma and urine samples were kept frozen at $-20^{\circ} \mathrm{C}$ until analysis. At months 0,12 , and 24 , cardiac output was determined by echocardiography.

Hemodynamic measurements. Blood pressure and heart rate were measured by the standard sphygmomanometric method after the patients had remained in the supine position for at least $30 \mathrm{~min}$. Cardiac output (CO) was measured by echocardiography at baseline and in months 12 and 24 as described by Uehara et al. (28). Total

Table I. Baseline Characteristics of the Subjects

\begin{tabular}{|c|c|c|c|c|}
\hline & & $\mathrm{GH}$ & Placebo & Control \\
\hline Number of patients & $n$ & 16 & 14 & 30 \\
\hline Sex & $\mathrm{m} / \mathrm{f}$ & $8 / 8$ & $6 / 8$ & $14 / 16$ \\
\hline Age & $\mathrm{yr}$ & $41.4 \pm 3.0$ & $41.6 \pm 2.6$ & $42.0 \pm 2.0$ \\
\hline Height & $\mathrm{cm}$ & $169.0 \pm 2.5$ & $167.6 \pm 2.9$ & $171.3 \pm 2.5$ \\
\hline Weight & $\mathrm{kg}$ & $79.5 \pm 4.2$ & $74.3 \pm 3.8$ & $76.9 \pm 3.4$ \\
\hline Systolic blood pressure & $\mathrm{mm} \mathrm{Hg}$ & $126.3 \pm 3.9$ & $120.5 \pm 4.2$ & $127.6 \pm 4.4$ \\
\hline Diastolic blood pressure & $\mathrm{mm} \mathrm{Hg}$ & $82.8 \pm 2.4$ & $80.9 \pm 1.6$ & $81.9 \pm 1.7$ \\
\hline Heart rate & $1 / \min$ & $69.3 \pm 2.3$ & $69.8 \pm 2.6$ & $70.3 \pm 3.1$ \\
\hline Total cholesterol & $\mathrm{mmol} / \mathrm{liter}$ & $7.2 \pm 0.4 *$ & $6.0 \pm 0.4$ & $4.9 \pm 0.1^{\ddagger}$ \\
\hline LDL cholesterol & $\mathrm{mmol} / \mathrm{liter}$ & $5.1 \pm 0.3^{*}$ & $4.3 \pm 0.4$ & $3.2 \pm 0.4^{\ddagger}$ \\
\hline HDL cholesterol & $\mathrm{mmol} / \mathrm{liter}$ & $1.1 \pm 0.1$ & $1.0 \pm 0.1$ & $1.1 \pm 0.1$ \\
\hline Triglycerides & $\mathrm{mmol} /$ liter & $2.44 \pm 0.40$ & $1.79 \pm 0.29$ & $1.51 \pm 0.27^{\ddagger}$ \\
\hline Hypercholesterolemia & $n$ & 11 & 4 & - \\
\hline
\end{tabular}

Data are expressed as mean \pm SEM. ${ }^{*} P<0.05$ between the groups of GH-deficient patients. ${ }^{\ddagger} P<0.05$ between controls and GH-deficient patients. 
peripheral resistance (TPR) was calculated from mean arterial blood pressure and cardiac output as TPR $=80 \times \mathrm{RR}_{\text {mean }} / \mathrm{CO}$ and expressed as dyne $\cdot \mathrm{s} \cdot \mathrm{cm}^{-5}$, with mean arterial blood pressure $\left(\mathrm{RR}_{\text {mean }}\right)=\mathrm{RR}_{\text {dias }}+$ $1 / 3 \times\left(R_{\text {sys }}-R_{\text {dias }}\right)$.

Biochemical analyses. Urinary $\mathrm{NO}_{2}{ }^{-} / \mathrm{NO}_{3}{ }^{-}$was determined as its pentafluorobenzyl derivative by gas chromatography-mass spectrometry as described previously $(26,29)$. Briefly, 100- $\mu$ l aliquots of urine were spiked with $250 \mathrm{ng}$ of $\left[{ }^{15} \mathrm{~N}\right] \mathrm{NO}_{3}{ }^{-}$- (MSD Isotopes; Merck Frosst, Montreal, Canada) as internal standard, acidified with $20 \mu \mathrm{l}$ of $0.1 \mathrm{~N}$ $\mathrm{HCl}$, and treated with $5 \mathrm{mg}$ of cadmium for $10 \mathrm{~min}$ at room temperature to reduce $\mathrm{NO}_{3}{ }^{-}$to $\mathrm{NO}_{2}{ }^{-}$. The suspension was then centrifuged, the supernatant decanted, and alkalinized with $10 \mu \mathrm{l}$ of $4 \mathrm{~N} \mathrm{NaOH}$, treated with $500 \mu \mathrm{l}$ of cold acetone $\left(-20^{\circ} \mathrm{C}\right)$ and centrifuged. $5 \mu l$ of pentafluorobenzyl bromide was added to the decanted supernatant and the mixture was allowed to react for $75 \mathrm{~min}$ at $50^{\circ} \mathrm{C}$. After cooling to room temperature, acetone was removed under nitrogen and the residue was extracted with $1 \mathrm{ml}$ of toluene. The toluene phase was taken up and dried over $\mathrm{Na}_{2} \mathrm{SO}_{4} .1-\mu \mathrm{l}$ aliquots thereof were injected into the gas chromatography-mass spectrometry.

Gas chromatography-mass spectrometry analysis was carried out on a triple stage quadrupole mass spectrometer TSQ 45 interfaced with a gas chromatograph 9611 (Finnigan MAT, San Jose, CA). An OV-1 fused silica capillary column $(25 \mathrm{~m} \times 0.25 \mathrm{~mm}$ i.d., $0.25-\mu \mathrm{m}$ film thickness) from Machery-Nagel (Düren, Germany) was used with helium as the carrier gas $(55 \mathrm{kPa})$. Negative ions were produced by chemical ionization using methane as the reactant gas $(65 \mathrm{~Pa})$ at an electron energy of $90 \mathrm{eV}$ and an electron current of $0.2 \mathrm{~mA}$. Quantitation was performed by selected ion monitoring at $\mathrm{m} / \mathrm{z} 46$ for endogenous $\mathrm{NO}_{2}{ }^{-} / \mathrm{NO}_{3}{ }^{-}$and $\mathrm{m} / \mathrm{z} 47$ for the internal standard. The detection limit of the method was $20 \mathrm{fmol}$ nitrite or nitrate. Intraassay variability was below $3.8 \%$

For the determination of cGMP, urine samples were thawed and centrifuged at 2,500 $\mathrm{g}\left(4^{\circ} \mathrm{C}, 10 \mathrm{~min}\right)$. Supernatants were diluted 1:500 in phosphate buffered saline and acetylated by a mixture of acetic acid anhydride/triethylamine. Cyclic GMP content was measured by radioimmunoassay using $\left[{ }^{125} \mathrm{I}\right] \mathrm{cGMP}$ as a tracer and globulin precipitation. The detection limit of the assay was $160 \mathrm{fmol} / \mathrm{ml}$.

Urinary creatinine was determined spectrophotometrically with the alkaline picric acid method in an automatic analyzer (Beckman Instruments, Galway, Ireland). The urinary excretion rates of $\mathrm{NO}_{3}{ }^{-}$ and cGMP were corrected by urinary creatinine concentration to reduce the variability due to differences in renal excretory function (25). Serum IGF-1 concentrations were measured by radioimmunoassay as described by Blum and Breier (30). Serum total cholesterol and HDL cholesterol, and serum triglyceride concentrations were measured according to standard spectrophotometric methods.

Calculations and statistical analysis. All data are presented as mean \pm SEM. Data analyses were performed on an intention-to-treat basis. Changes in hemodynamic parameters were tested for statistical significance using ANOVA followed by Scheffé $f$ test with correction of $\alpha$ for multiple tests $(31,32)$. The urinary excretion rates of nitrate and cyclic GMP, and the plasma concentrations of IGF-1 were compared by calculating each individual's area under the concentration: time curve (AUC) for months 1-12 and 13-24, and tested for statistically significant differences by ANOVA followed by Fisher's protected least significant difference test. Statistical significance was accepted in all cases for $P<0.05$.

\section{Results}

Baseline measurements. Baseline plasma IGF-1 concentration was $99.1 \pm 7.7 \mathrm{ng} / \mathrm{ml}$ in growth hormone-deficient patients, and $181.5 \pm 8.3 \mathrm{ng} / \mathrm{ml}$ in age- and sex-matched healthy controls $(P<0.05)$. Urinary nitrate excretion was $96.8 \pm 7.4 \mu \mathrm{mol} / \mathrm{mmol}$ creatinine at baseline in growth hormone-deficient adults, as compared with $167.3 \pm 7.5 \mu \mathrm{mol} / \mathrm{mmol}$ creatinine in age- and sex-matched healthy controls $(P<0.05$; Fig. 1$)$. Similarly, uri-

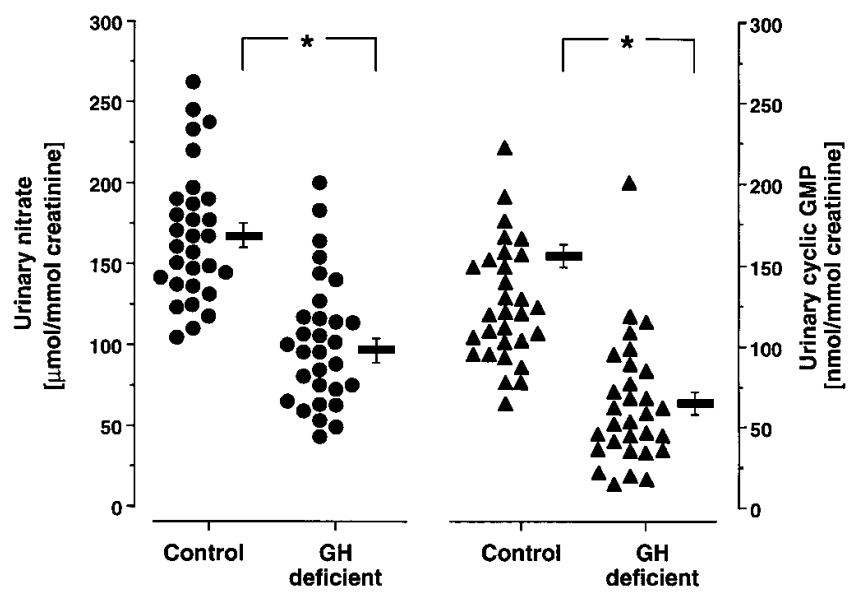

Figure 1. Urinary excretion rates of nitrate and cyclic GMP in adult patients with acquired growth hormone deficiency ( $G H$ deficient) and age- and sex-matched healthy controls (Control). Each point represents one single subject. $n=30$ in both groups. The horizontal bars indicate mean \pm SEM. $* P<0.05$.

nary cyclic GMP excretion was significantly lower at baseline in growth hormone-deficient patients $(63.6 \pm 7.1 \mathrm{nmol} / \mathrm{mmol}$ creatinine) than in healthy controls $(155.2 \pm 6.9 \mathrm{nmol} / \mathrm{mmol}$ creatinine; $P<0.05$; Fig. 1 ).

Clinical observations. Of the 30 patients randomized, 16 were allocated to the $\mathrm{GH}$ group and 14 to the placebo group. 20 patients experienced side effects during r-hGH treatment. Symptoms were peripheral oedema $(n=15)$, arthralgia $(n=$ $9)$, carpal tunnel compression $(n=8)$, myalgia $(n=5)$, and headache $(n=5)$; they were most often observed in months 3-6. During placebo administration, 8 patients experienced side effects: peripheral oedema $(n=3)$, arthralgia $(n=4)$, ex-

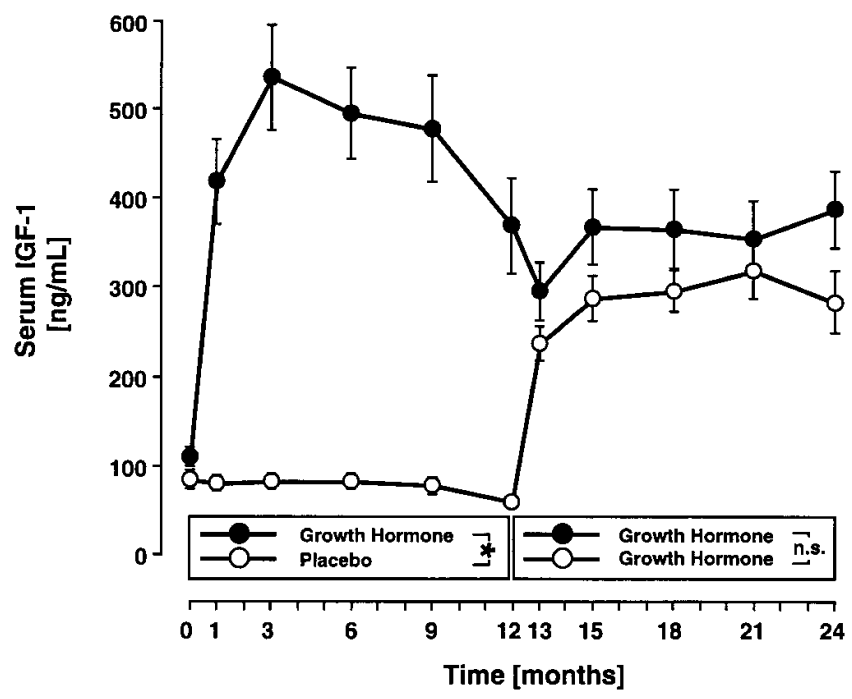

Figure 2. Plasma concentrations of IGF-1 in patients with growth hormone deficiency treated with r-hGH from months 1-24 (GH group; ), or treated with placebo from months 1-12 and with r-hGH from months 13-24 (Placebo group; $\bigcirc$ ). Statistical analyses were performed by calculating the areas under the plasma concentration:time curves for months 1-12 and 13-24, and compared by Fisher's protected least significant difference test. $* P<0.05$. 
Table II. Endocrinologic Diagnoses and Replacement Treatment

\begin{tabular}{lcc}
\hline & GH & Placebo \\
\hline Original diagnosis & $n$ & $n$ \\
Craniopharyngioma & 3 & 2 \\
Chromophobe adenoma & 5 & 5 \\
Eosinophilic adenoma & 0 & 1 \\
Unspecified adenoma & 3 & 5 \\
Prolactinoma & 0 & 1 \\
Suprasellar epidermoid cyst & 0 & 1 \\
Empty sella syndrome & 1 & 1 \\
Posttraumatic hypopituitarism & 1 & 0 \\
Sheehan's syndrome & 1 & 0 \\
& $y r$ & $y r$ \\
Time since primary diagnosis & $6.2 \pm 1.1$ & $7.1 \pm 1.3$ \\
$\quad$ range & $2.5-14$ & $2.5-22$ \\
Replacement treatment & $n$ & $n$ \\
Thyroxine & 15 & 14 \\
Cortisol & 15 & 13 \\
Sex steroids & 15 & 14 \\
Desmopressin & 6 & 6 \\
& & \\
\hline
\end{tabular}

Data are expressed as mean \pm SEM. There were no statistically significant differences between the two groups.

haustion and fatigue $(n=7)$, or headache $(n=6)$. In 16 patients, the dose of r-hGH had to be reduced, after which the symptoms subsided and the study could be continued in 14 patients. A total of 3 patients dropped out during the course of the study ( 1 during placebo, 2 during r-hGH administration), so that 27 patients completed all phases of the study. Reasons for drop-out were: onset of a generalized tonic-clonic seizure ( $n=1$, during placebo administration), persistence of severe peripheral oedema during r-hGH administration $(n=1)$, and incidence of a carpal tunnel syndrome ( $n=1$, during r-hGH administration).
Serum IGF-1 and lipid concentrations. In the GH group, plasma IGF-1 increased to $418.8 \pm 48.4 \mathrm{ng} / \mathrm{ml}$ within the first month of treatment. Plasma IGF-1 concentrations remained above $300 \mathrm{ng} / \mathrm{ml}$ for the entire study period in this group (Fig. 2). In the placebo group, plasma IGF-1 remained at baseline level during the first 12 mo of placebo administration. After initiation of r-hGH treatment in this group, starting in month 12, plasma IGF-1 concentration increased to a level that was not significantly different from the GH group.

Serum total cholesterol and LDL lipoprotein concentrations were higher in the GH group at baseline than in the placebo group; but there was no significant difference in total cholesterol, LDL cholesterol, HDL cholesterol, or triglycerides throughout the rest of the study between the GH and placebo groups (Table II).

Effects of $r$-hGH on urinary nitrate and cyclic GMP excretion rates. Urinary nitrate excretion significantly increased in the $\mathrm{GH}$ group to $146.0 \pm 28.5 \mu \mathrm{mol} / \mathrm{mmol}$ creatinine, whereas in the placebo group it remained on a low, stable plateau during the first 12 mo of placebo administration (Fig. $3 \mathrm{~A}$ ). After $\mathrm{r}$-hGH treatment was also started in the placebo patients, urinary nitrate excretion in this group increased to a level almost identical to that in the GH group. Mean urinary nitrate excretion during months $1-12$ was $126.4 \pm 9.9 \mu \mathrm{mol} / \mathrm{mmol}$ creatinine in the GH group and $88.5 \pm 5.0 \mu \mathrm{mol} / \mathrm{mmol}$ creatinine in the placebo group $(P<0.05)$. In months $13-24$, mean urinary nitrate excretion was $129.0 \pm 10.2$ and $132.3-9.1 \mu \mathrm{mol} / \mathrm{mmol}$ creatinine, respectively $(P=\mathrm{NS})$.

The temporal pattern of cyclic GMP excretion was similar to that of nitrate excretion, although the differences between both groups were not quite as obvious (Fig. $3 \mathrm{~B}$ ). Mean urinary cyclic GMP excretion was $91.6 \pm 10.4 \mathrm{nmol} / \mathrm{mmol}$ creatinine in the $\mathrm{GH}$ group and $83.6 \pm 5.7 \mathrm{nmol} / \mathrm{mmol}$ creatinine in the placebo group during the first 12 months $(P<0.05)$. In the second half of the study period, mean urinary cyclic GMP excretion was $88.5 \pm 8.9$ and $109.8 \pm 9.5 \mathrm{nmol} / \mathrm{mmol}$ creatinine, respectively $(P=\mathrm{NS})$. The urinary excretion rates of nitrate and cyclic GMP were significantly correlated with $r=0.61(P<$ 0.01). There was a linear correlation between plasma IGF-1
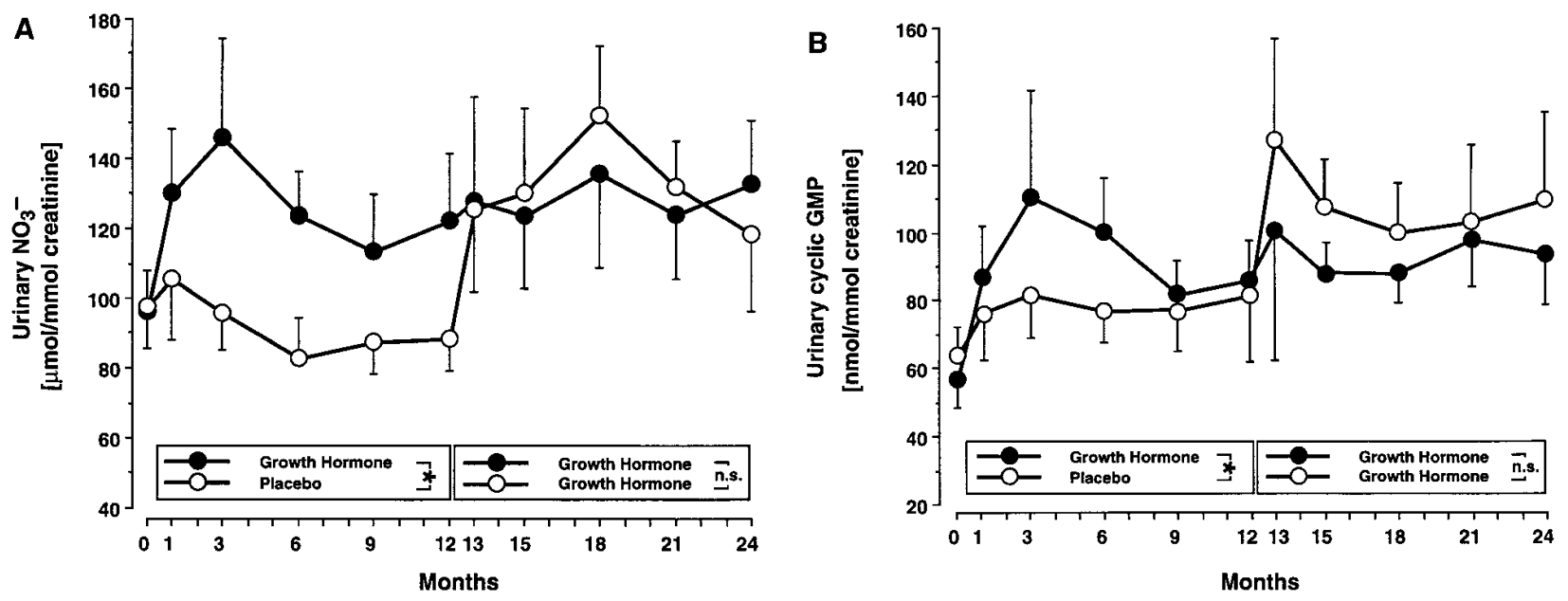

Figure 3. Urinary excretion rates of nitrate, the oxidative metabolite of NO $(A)$, and cyclic GMP, its second messenger $(B)$, in patients with growth hormone deficiency treated with r-hGH from months 1-24 (GH group; $)$ ), or treated with placebo from months 1-12 and with r-hGH from months 13-24 (Placebo group; $\bigcirc$ ). Statistical analyses were performed by calculating the areas under the urinary excretion:time curves for months $1-12$ and 13-24, and compared by Fisher's protected least significant difference test. $* P<0.05$. 


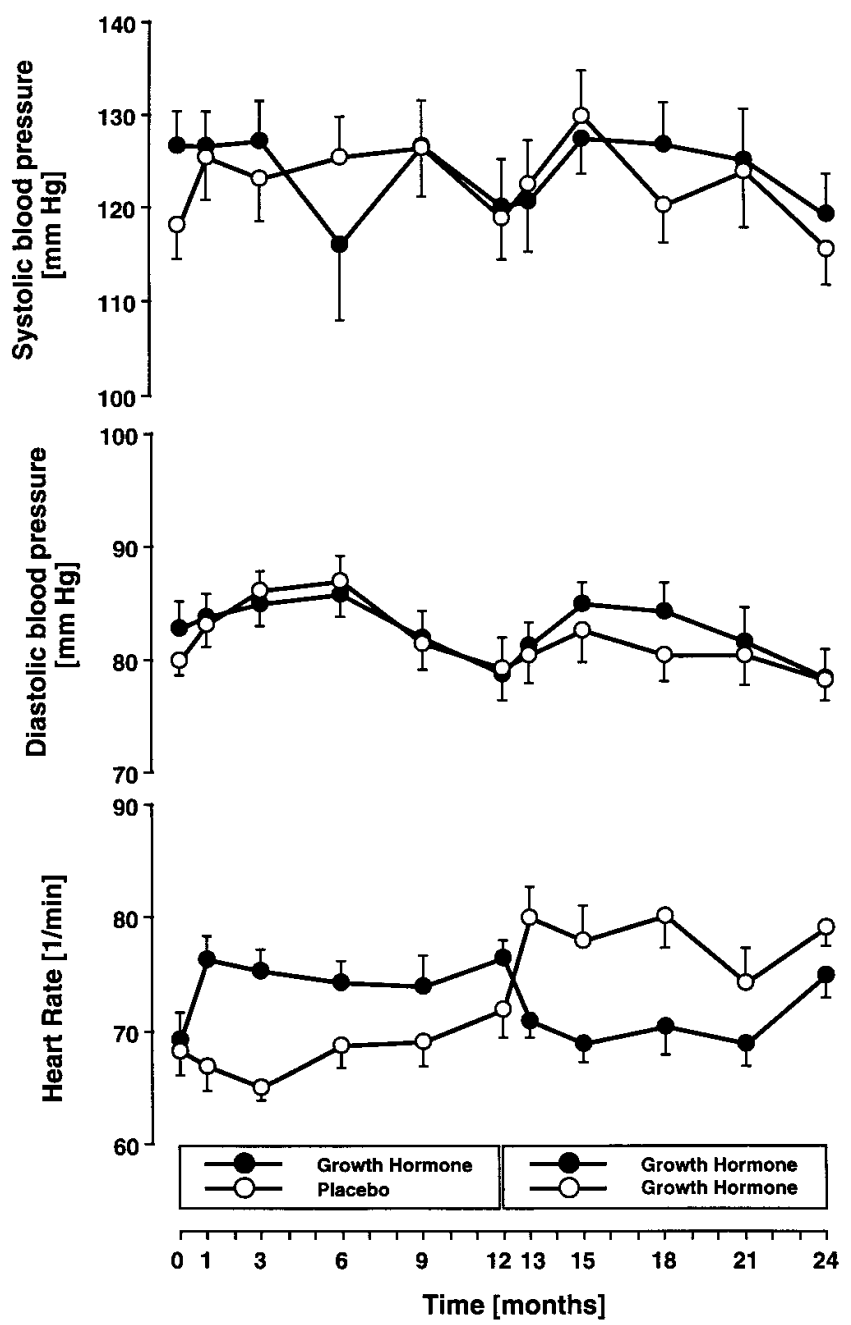

Figure 4. Systolic and diastolic blood pressures and heart rates in patients with growth hormone deficiency treated with r-hGH from months 1-24 (GH group; ), or treated with placebo from months 1-12 and with r-hGH from months 13-24 (Placebo group; $\bigcirc$ ). concentrations and the urinary excretion rates of nitrate $(r=$ $0.26, P<0.05)$ and cyclic GMP $(r=0.32, P<0.05)$.

Hemodynamic effects of $r-h G H$. Diastolic and systolic blood pressure were not significantly affected by r-hGH or placebo (Fig. 4); however, r-hGH significantly increased heart rates by a mean of $8.7 \pm 0.7 \%$. This effect was observed in the $\mathrm{GH}$ group within the first month of treatment, and in the placebo group within 1 mo after these patients had also been treated with $\mathrm{r}-\mathrm{hGH}$ in the second half of the study period (each $P<0.05$; Fig. 4).

Cardiac output was $3.8 \pm 0.2$ liters $/ \mathrm{min}$ at baseline. At month 12 , it was increased by $39.1 \pm 9.9 \%$ in the $\mathrm{GH}$ group and remained unchanged in the placebo group. At month 24 , cardiac output was also increased in the placebo patients who were now also treated with $\mathrm{r}-\mathrm{hGH}(+28.0 \pm 6.7 \%, P<0.05)$. There was no significant difference between the groups at this

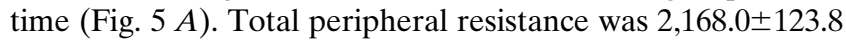
dyne $\cdot \mathrm{s} \cdot \mathrm{cm}^{-5}$ at baseline with no significant difference between the groups. It was significantly reduced by $\mathrm{r}-\mathrm{hGH}$ in both groups (GH group: $-36.3 \pm 3.8 \%$, month 1 vs. month 12 ; placebo group: $-27.7 \pm 3.9 \%$, month 24 vs. month 12 ; each $P<$ 0.05 ), but was unchanged by placebo (Fig. $5 B$ ).

The decrease in total peripheral resistance was correlated to the increases in urinary nitrate and cGMP excretion rates with $r=0.34(P<0.05)$ and $r=0.41(P<0.01)$, respectively.

\section{Discussion}

The salient findings of the present study are that (a) systemic NO formation is impaired in adult patients with acquired hypopituitarism, and (b) NO formation is significantly increased during substitution therapy with recombinant human growth hormone. (c) This increase in systemic NO formation was associated with a decrease of total peripheral resistance and an increase in heart rate.

The risk of cardiovascular disease is increased in patients with growth hormone deficiency. Recent studies have related the increased incidence of cardiovascular disease to the high
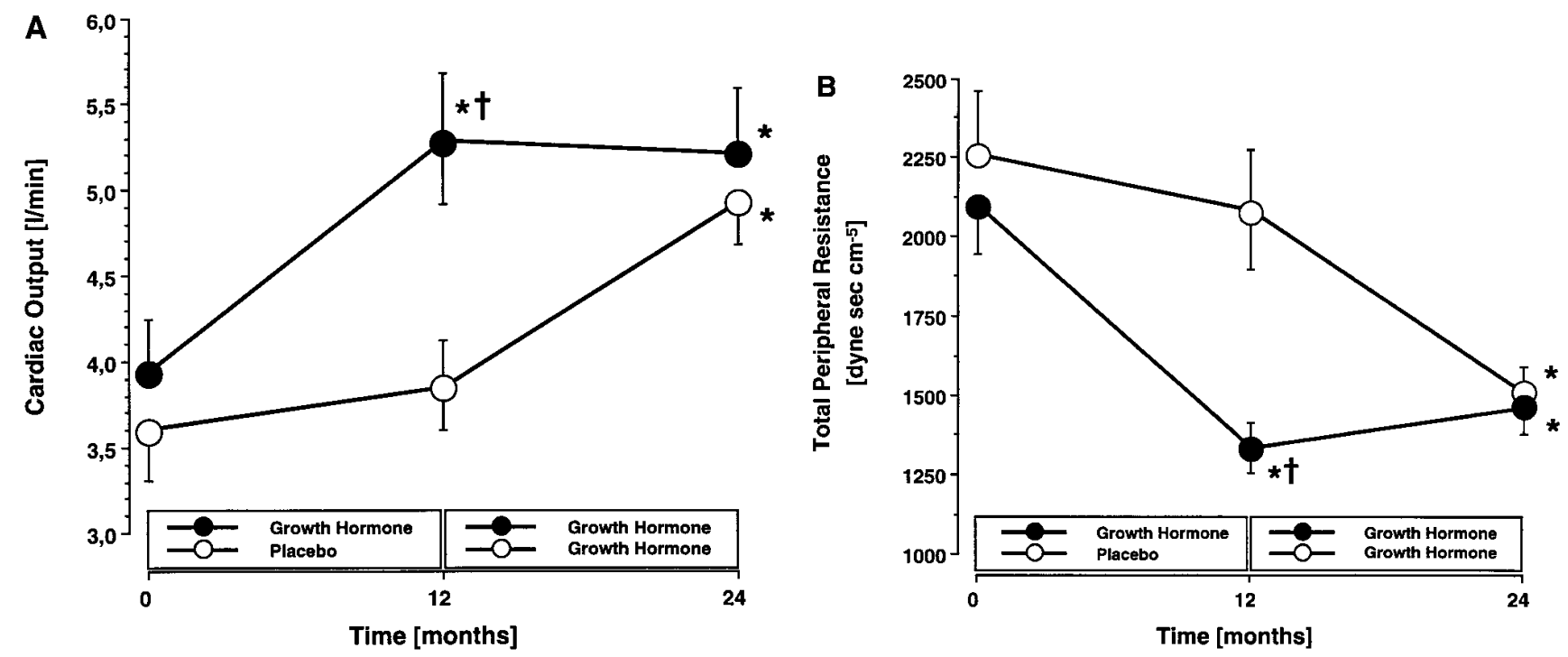

Figure 5. Cardiac output $(A)$ and calculated total peripheral resistance $(B)$ as measured at baseline (month 0 ), and in months 12 and 24 by echocardiography in patients with growth hormone deficiency. Patients were treated with $\mathrm{r}$-hGH from months $1-24$ (GH group; $\bullet$ ), or treated with placebo from months $1-12$ and with $\mathrm{r}$-hGH from months $13-24$ (Placebo group; $\bigcirc$ ). ${ }^{*} P<0.05$ vs. baseline. ${ }^{\ddagger} P<0.05$ between the groups. 
Table III. Measurements of Serum Lipid Concentrations in Patients with Growth Hormone Deficiency Treated with r-hGH from Month 1-24 (GH), or Placebo from Month 1-12, and $r$-hGH from Month 13-24 (Placebo)

\begin{tabular}{|c|c|c|c|c|}
\hline & & \multicolumn{3}{|c|}{ Month } \\
\hline & & 0 & 12 & 24 \\
\hline & & & nmol/liter & \\
\hline \multirow[t]{2}{*}{ Total cholesterol } & $\mathrm{GH}$ & $7.2 \pm 0.4^{*}$ & $6.2 \pm 0.4$ & $6.0 \pm 0.3$ \\
\hline & Placebo & $6.0 \pm 0.4$ & $6.0 \pm 0.3$ & $6.0 \pm 0.4$ \\
\hline \multirow[t]{2}{*}{ LDL cholesterol } & $\mathrm{GH}$ & $5.1 \pm 0.3^{*}$ & $4.3 \pm 0.4$ & $4.0 \pm 0.4$ \\
\hline & Placebo & $4.3 \pm 0.4$ & $4.3 \pm 0.3$ & $4.1 \pm 0.4$ \\
\hline \multirow[t]{2}{*}{ HDL cholesterol } & $\mathrm{GH}$ & $1.1 \pm 0.1$ & $1.2 \pm 0.1$ & $1.2 \pm 0.1$ \\
\hline & Placebo & $1.0 \pm 0.1$ & $1.1 \pm 0.1$ & $1.1 \pm 0.1$ \\
\hline \multirow[t]{2}{*}{ Triglycerides } & $\mathrm{GH}$ & $2.44 \pm 0.40$ & $1.68 \pm 0.26$ & $1.80 \pm 0.20$ \\
\hline & Placebo & $1.79 \pm 0.29$ & $1.70 \pm 0.26$ & $1.87 \pm 0.29$ \\
\hline
\end{tabular}

Data are expressed as mean \pm SEM. $* P<0.05$ for GH vs. Placebo group at baseline. There were no statistically significant differences between the two groups at any of the other time points.

prevalence of hypertension (4) and hyperlipoproteinemia in these patients $(2,33,34)$. In a retrospective study of 12 adults with pituitary deficiency, the prevalence of both hyperlipidemia (77\%) and hypertension (18\%) was higher than might have been expected from age and sex (35).

Growth hormone substitution therapy has been shown to reduce the cardiovascular risk factor profile and physical performance in patients with growth hormone deficiency (36-40). Previous short term studies have revealed that r-hGH favorably affects lipoprotein metabolism, inducing an increase in LDL cholesterol clearance by activating the hepatic LDL receptor $(41)$ with a decrease $(36,42)$ or no change in total serum cholesterol (38), and an increase in serum HDL concentration $(43,44)$.

Similar inconsistent results have been found for the effects of r-hGH on blood pressure: a favorable decrease in diastolic blood pressure has been noted in a study of 10 growth hormone-deficient patients (9), although hypertension was also observed as a side effect of growth hormone treatment (36). Other authors also reported no or only marginal increases in blood pressure, although there usually is salt and water retention during $\mathrm{r}-\mathrm{hGH}$ therapy $(40,45)$. This discrepancy between the salt- and water-retentive effect of $\mathrm{r}-\mathrm{hGH}$ and the absence of major increases in blood pressure has remained unexplained (45). However, the observation of increased heart rates during $\mathrm{r}-\mathrm{hGH}$ therapy in our present study as well as in studies previously reported by others $(9,37)$ points to a decreased peripheral vascular resistance induced by $\mathrm{r}-\mathrm{hGH}$ administration. This effect has been directly proven in the present study as well as by Caidahl et al. (9).

Moreover, intimal thickening and accelerated progression of atheromatous plaques, and reduced distensibility of the arterial wall have been found by high resolution ultrasound measurements in the carotid and femoral arteries of patients with hypopituitarism in a case-control study (46). Reduced distensibility of the aorta has been observed in another study of growth hormone-deficient patients (47). Both studies may point to a possible decrease in vascular compliance, similar to that seen in atherosclerotic arteries, in growth hormone-deficient patients, the mechanism of which has remained unclear.

One important finding of the present study is that growth hormone deficiency is associated with decreased systemic NO formation. Impaired NO activity has been shown to play an important role in the pathogenesis of cardiovascular disease. The urinary excretion rates of nitrate, the final oxidative metabolite of NO (48), and of its second messenger cyclic GMP have been shown by us and others to be useful indicators of systemic NO formation rates in vivo $(27,49,50)$. We have recently demonstrated that the urinary excretion rates of nitrate and cyclic GMP closely mirror systemic NO synthesis rates independently of renal excretory function, provided that the excretion data are related to urinary creatinine (25). Baseline urinary nitrate and cyclic GMP excretion rates were found substantially lower in the growth hormone-deficient patients than in age- and sex-matched controls screened in the present study. Indeed, these indices of NO formation were as low in patients with growth hormone deficiency as in patients with peripheral arterial occlusive disease and generalized atherosclerosis (nitrate, $121.4 \pm 8.3 \mu \mathrm{mol} / \mathrm{mmol}$ creatinine; cyclic GMP, $114.3 \pm 12.8 \mathrm{nmol} / \mathrm{mmol}$ creatinine) (R.H. Böger and S.M. Bode-Böger, unpublished observations), whereas those in the control group were comparable with the values we previously found in young healthy volunteers (49).

Decreased NO activity has been shown to be associated with impaired endothelium-dependent vasodilator capacity $(20,51)$, increased platelet aggregability (52), enhanced endothelial leukocyte adhesion $(53,54)$, and intimal thickening $(20$, 22). These pathophysiological consequences of impaired NO activity resemble the array of cardiovascular sequelae reported for growth hormone deficiency $(4,40)$. Therefore, impaired NO formation may contribute to the increased risk of cardiovascular disease in growth hormone-deficient patients.

The cause of impaired NO activity in atherosclerotic patients remains unclear. It may be related to decreased NO synthesis or to increased oxidative inactivation of NO $(19,55)$. Increased LDL lipoprotein concentrations have been shown to impair nitric oxide formation and/or activity in vitro $(56,57)$. This may also have contributed to a certain degree to decreased baseline NO formation in the growth hormone-deficient patients in our present study, although for two reasons this may not be the main cause: firstly, although the LDL concentration was significantly lower in GH group at baseline as compared with the placebo group, there was no significant difference in the indices of NO formation between the groups. Secondly, a similar increase in urinary nitrate and cyclic GMP excretion was observed in both groups during the administration of r-hGH (GH group: months 1 vs. $0,+40.4 \pm 17.5 \%$ for nitrate and $+42.2 \pm 15.5 \%$ for cyclic GMP; placebo group: months 13 vs. $12,+60.7 \pm 38.6 \%$ for nitrate and $+57.2 \pm 33.0 \%$ for cyclic GMP), although in the placebo group no reduction in serum LDL cholesterol concentration was induced by $\mathrm{r}-\mathrm{hGH}$ treatment.

There may be a more evident reason for impaired NO activity in growth hormone-deficient patients, as growth hormone exerts at least part of its effects via IGF-1, and IGF-1 has been shown to have a direct stimulatory effect on NO synthesis by cultured endothelial cells (17). NO in turn is responsible for the hemodynamic effects of IGF-1 in isolated perfused kidneys (16). The patients in our present study were selected under the premise that their serum IGF-1 levels were below the 
fifth percentile according to age and sex (27). Thus, the low urinary nitrate and cyclic GMP excretion rates may have reflected a decreased IGF-1-stimulated endothelial NO synthesis.

There are several lines of evidence to strengthen this interpretation: (a) low basal IGF-1 serum concentrations were associated with low basal urinary nitrate and cyclic GMP excretion rates. (b) The increase in serum IGF-1 concentrations during $\mathrm{r}$-hGH treatment was associated with increased $\mathrm{NO}$ index metabolic excretion. During r-hGH therapy, urinary nitrate excretion reached values that were comparable to healthy agematched controls. (c) Urinary nitrate excretion was correlated to the hemodynamic response to $\mathrm{r}-\mathrm{hGH}$ therapy.

Recent experimental evidence supports our present suggestion that NO release may be involved in the beneficial cardiovascular effects of growth hormone therapy, as it could be demonstrated by Motani et al. (58) that IGF-1 modulates monocyte adhesion to cultured endothelial cells via NO. Monocyte adhesion is regarded as one important, early step in atherogenesis (53), as monocytes present in the vascular wall contribute to the progression of atheromatous lesions; e.g., by releasing superoxide anions and growth factors $(23,59)$.

In conclusion, our present data strongly suggest that NO production is impaired in adult patients with untreated growth hormone deficiency. Treatment with recombinant human growth hormone increases nitric oxide formation. The beneficial cardiovascular effects of growth hormone in these patients may thus be mediated via IGF-1:NO:cyclic GMP.

\section{Acknowledgments}

The authors thank M.-T. Suchy and F.-M. Gutzki for their excellent technical assistance in performing the nitrate and cyclic GMP analyses, as well as H. Renftel-Heine, A. Preckel, M. Darnedde, and B. Bremer for their excellent help in performing the biochemical analyses, and to Drs. A. Mügge and W. Daniel, Department of Cardiology (Hannover Medical School), for performing the echocardiographic measurements. We also thank our colleagues Drs. Rieger, Siegert, Müller-Marhenke, Welper, and Küthemeyer, who were involved in the treatment of the patients. R-hGH and placebo were provided in blinded vials by Novo Nordisk A/S, Denmark.

\section{References}

1. Rosén, T., and B.A. Bengtsson. 1990. Premature mortality due to cardiovascular disease in hypopituitarism. Lancet. 336:285-288.

2. Merimee, T., W. Hollander, and E. Fineberg. 1972. Studies of hyperlipidemia in the hGH-deficient state. Metabolism. 21:1053-1061.

3. Blackett, P.R., P.K. Weech, W.J. McConathy, and J.D. Fesmire. 1982. Growth hormone in the regulation of hyperlipidemia. Metabolism. 31:117-120.

4. Rosén, T., S. Edén, G. Larson, L. Wilhelmsen, and B.A. Bengtsson. 1993. Cardiovascular risk factors in adult patients with growth hormone deficiency. Acta Endocrinol. 128:195-200.

5. Friedman, M., S.O. Byers, R.H., Rosenman, C.H. Li, and R. Neuman. 1974. Effect of subacute administration of human growth hormone on various serum lipid and hormone levels of hypercholesterolemic and normocholesterolemic subjects. Metabolism. 23:905-912.

6. Lapidus, L., C. Bengtsson, B. Larsson, K. Pennert, E. Rybo, and L. Sjöström. 1984. Distribution of adipose tissue and risk of cardiovascular disease and death: a 12 year follow-up of participants in the population study of women in Gothenburg, Sweden. Br. Med. J. 289:1257-1261.

7. Larsson, B., K. Svärdsudd, L. Welin, L. Wilhelmsen, P. Björntorp, and G. Tibblin. 1984. Abdominal adipose tissue distribution, obesity, and risk of cardiovascular disease and death: 13 year follow-up of participants in the study of men born in 1913. Br. Med. J. 288:1401-1404.

8. Thuesen, L., J.S. Christiansen, K. E. Sorensen, J.O.L. Jorgensen, H. Orskov, and P. Henningsen. 1988. Increased myocardial contractility following growth hormone administration in normal man. Dan. Med. Bull. 35:193-196.

9. Caidahl, K., S. Edén, and B.A. Bengtsson. 1994. Cardiovascular and renal effects of growth hormone. Clin. Endocrinol. 40:393-400.
10. Daughaday, W.H., and P. Rotwein. 1989. Insulin-like growth factors I and II. Peptide, messenger ribonucleic acid and gene structures, serum, and tissue concentrations. Endocr. Rev. 10:68-91.

11. Sacca, L., A. Cittadini, and S. Fazio. 1994. Growth hormone and the heart. Endocr. Rev. 15:555-573.

12. Krieg, R.J., F. Santos, and J.C.M. Chan. 1995. Growth hormone, insulinlike growth factor and the kidney. Kidney Int. 48:321-336.

13. Landin-Wilhelmsen, K., L. Wilhelmsen, G. Lappas, T. Rosén, G. Lindstedt, P.A. Lundberg, and B.A. Bengtsson. 1994. Serum insulin-like growth factor $\mathrm{I}$ in a random population sample of men and women: relation to age, sex, smoking habits, coffee consumption and physical activity, blood pressure and concentrations of plasma lipids, fibrinogen, parathyroid hormone and osteocalcin. Clin. Endocrinol. 41:351-357.

14. Bar, R.S., M. Boes, B.L. Dake, B.A. Booth, S.A. Henley, and A. Sandra. 1988. Insulin, insulin-like growth factors, and vascular endothelium. Am. J. Med. 85(Suppl. 5a):59-70.

15. Wu, H.Y., C.J. Yue, K.Y. Chyu, W.A. Hsueh, and T.M. Chan. 1994. Endothelial-dependent vascular effects of insulin and insulin-like growth factor I in the perfused rat mesenteric artery and aortic ring. Diabetes. 43:1027-1032.

16. Haylor, J., I. Singh, and A.M. El Nahas. 1991. Nitric oxide inhibitor prevents vasodilation by insulin-like growth factor I. Kidney Int. 39:333-335.

17. Tsukahara, H., D.V. Gordienko, B. Tonshoff, M.C. Gelato, and M.S. Goligorsky. 1994. Direct demonstration of insulin-like growth factor-I-induced nitric oxide production by endothelial cells. Kidney Int. 45:598-604.

18. Moncada, S., and E.A. Higgs. 1993. The L-arginine-nitric oxide pathway. N. Engl. J. Med. 329:2002-2012.

19. Radomski, M.W., and E. Salas. 1995. Nitric oxide-biological mediator, modulator and factor of injury: its role in the pathogenesis of atherosclerosis. Atherosclerosis. 118(Suppl.):S69-S80.

20. Böger, R.H., S.M. Bode-Böger, A. Mügge, S. Kienke, R. Brandes, A Dwenger, and J.C. Frölich. 1995. Supplementation of hypercholesterolaemic rabbits with L-arginine reduces the vascular release of superoxide anions and restores NO production. Atherosclerosis. 117:273-284.

21. Küng, C.F., and T.F. Lüscher. 1995. Different mechanisms of endothelial dysfunction with aging and hypertension in rat aorta. Hypertension (Dallas). 25:194-200.

22. Cooke, J.P., A.H. Singer, P. Tsao, P. Zera, R.A. Rowan, and M.E. Billingham. 1992. Antiatherosclerotic effects of L-arginine in the hypercholesterolemic rabbit. J. Clin. Invest. 90:1168-1172.

23. Candipan, R.C., B. Wang, R. Buitrago, P.S. Tsao, and J.P. Cooke. 1996. Regression or progression. Dependency on vascular nitric oxide. Arterioscler. Thromb. Vasc. Biol. 16:44-50.

24. Böger, R.H., S. M. Bode-Böger, U. Gerecke, and J.C. Frölich. 1994 Long-term administration of L-arginine, L-NAME, and the exogenous NO donor molsidomine modulate urinary nitrate and cyclic GMP excretion in ratscorrelation with vascular reactivity. Cardiovasc. Res. 28:494-499.

25. Böger, R.H., S.M. Bode-Böger, U. Gerecke, F.M. Gutzki, D. Tsikas, and J.C. Frölich. 1996. Urinary $\mathrm{NO}_{3}^{-}$excretion as an indicator of nitric oxide formation in vivo during oral administration of L-arginine or L-NAME in rats. Clin. Exp. Pharmacol. Physiol. 23:11-15.

26. Bode-Böger, S.M., R.H. Böger, H. Alfke, D. Heinzel, D. Tsikas, A. Creutzig, K. Alexander, and J.C. Frölich. 1996. L-arginine induces nitric oxidedependent vasodilation in patients with critical limb ischemia. A randomized, controlled study. Circulation. 93:85-90.

27. Juul, A., P. Bang, N.T. Hertel, K. Main, P. Dalgaard, K. Jörgensen, J. Müller, K. Hall, and N.E. Skakkebaek. 1994. Serum insulin-like growth factor-1 in 1030 healthy children, adolescents, and adults: relation to age, sex, stage of puberty, testicular size, and body mass index. J. Clin. Endocrinol. Metab. 78: $744-752$.

28. Uehara, Y., M. Koga, and M. Takahashi. 1995. Determination of cardiac output by echocardiography. J. Vet. Med. Sci. 57:401-407.

29. Tsikas, D., R.H. Böger, S.M. Bode-Böger, F.M. Gutzki, and J.C Frölich. 1994. Quantification of nitrite and nitrate in human urine and plasma as pentafluorobenzyl derivatives by gas chromatography-mass spectrometry using their ${ }^{15} \mathrm{~N}$-labelled analogs. J. Chromatogr. B Biomed. Appl. 661:185-191.

30. Blum, W.F., and B.H. Breier. 1994. Radioimmunoassays for IGFs and IGFBPs. Growth Regul. 4(Suppl. 1):11-19.

31. Fisher, L.D., and G. van Belle. 1993. Multiple comparisons. In Biostatistics. A Methodology for the Health Sciences. LD Fisher and G. van Belle, editors. John Wiley \& Sons, New York. 596-629.

32. Ludbrook, J. 1994. Repeated measurements and multiple comparisons in cardiovascular research. Cardiovasc. Res. 28:303-311.

33. Cuneo, R.C., F. Salomon, G.F. Watts, R. Hesp, and P.H. Sönksen. 1993. Growth hormone treatment improves serum lipids and lipoproteins in adults with growth hormone deficiency. Metabolism. 42:1519-1523.

34. Rosén, T., G. Johansson, J.O. Johansson, and B.A. Bengtsson. 1995. Consequences of growth hormone deficiency in adults and the benefits of recombinant growth hormone treatment. Horm. Res. (Basel). 43:93-99.

35. Wuster, C.H.R., E. Slenczka, and R. Ziegler. 1991. Erhöhte Prävalenz von osteoporose und arteriosklerose bei konventionell substituierter hypophysenvorderlappen-insuffizienz: bedarf einer zusätzlichen wachstumshormonsubstitution? Klin. Wochenschr. 69:769-773. 
36. Salomon, F., R.C. Cuneo, R. Hesp, and P.H. Sönksen. 1989. The effects of treatment with recombinant human growth hormone on body composition and metabolism in adults with growth hormone deficiency. N. Engl. J. Med. 321: 1797-1803.

37. Jörgensen, J.O.L., L. Thuesen, T. Ingemann-Hansen, S.A. Pedersen, J. Jörgensen, N.E. Skakkebaek, and J.S. Christiansen. 1989. Beneficial effects of growth hormone treatment in GH-deficient adults. Lancet. I:1221-1225.

38. Whitehead, H., C. Boreham, E.M. McIlrath, B. Sheridan, L. Kennedy, A.B. Atkinson, and D.R. Hadden. 1992. Growth hormone treatment of adults with growth hormone deficiency. Results of a 13-month placebo controlled cross-over study. Clin. Endocrinol. 36:45-52.

39. Bengtsson, B.A., S. Edén, L. Lönn, H. Kvist, A. Stokland, G. Lindstedt, I. Bosaeus, J. Tölli, L. Sjöström, and O. G. P. Isaksson. 1993. Treatment of adults with growth hormone $(\mathrm{GH})$ deficiency with recombinant human GH. $J$. Clin. Endocrinol. Metab. 76:309-317.

40. Riedel, M., G. Brabant, K. Rieger, and A. von zur Mühlen. 1994. Growth hormone therapy in adults: rationales, results, and perspectives. Exp. Clin. Endocrinol. 102:273-283.

41. Rudling, M., G. Norstedt, H. Olivecrona, E. Reinér, J.A. Gustafsson, and B. Angelin. 1992. Importance of growth hormone for the induction of hepatic low density lipoprotein receptors. Proc. Natl. Acad. Sci. USA. 89:69836987.

42. Cuneo, R.C., F. Salomon, C.M. Wiles, R. Hesp, and P.H. Sönksen. 1991. Growth hormone treatment in growth hormone-deficient adults. I. Effects on muscle mass and strength. J. Appl. Physiol. 7:688-694.

43. Rosén, T., G. Johansson, P. Hallgren, K. Caidahl, I. Bosaeus, and B.A. Bengtsson. 1994. Beneficial effects of 12 months replacement therapy with recombinant human growth hormone to growth hormone deficient adults. Endocrinol. Metab. 1:55-66.

44. Edén, S., O. Wiklund, J. Oscarsson, T. Rosén, and B.A. Bengtsson. 1993. Growth hormone treatment of growth hormone deficient adults results in a marked increase in lipoprotein (a) concentrations but also in increased HDL cholesterol concentrations. Arterioscler. Thromb. 13:296-301.

45. Hoffman, D.M., L. Crampton, C. Srenia, T.V. Nguyen, and K.K.Y. Ho. 1996. Short term growth hormone $(\mathrm{GH})$ treatment of GH-deficient adults increases body sodium and extracellular water, but not blood pressure. J. Clin. Endocrinol. Metab. 81:1123-1128.

46. Markussis, V., S.A. Beshyah, C. Fisher, P. Sharp, A.N. Nicolaides, and D.G. Johnston. 1992. Detection of premature atherosclerosis by high-resolution ultrasound in symptom-free hypopituitary adults. Lancet (N. Am. Ed.). 340: $1188-1192$

47. Lehmann, E.D., D.K. Hopkins, A.J. Weissberger, R.G. Gosling, and
P.H. Sönksen. 1993. Aortic distensibility in growth hormone deficient adults (Letter). Lancet (N. Am. Ed.). 341:309.

48. Wennmalm, A., G. Benthin, A. Edlund, L. Jungersten, N. KielerJensen, S. Lundin, U. Nathorst-Westfelt, A.S. Petersson, and F. Waagstein 1993. Metabolism and excretion of nitric oxide in humans. Circ. Res. 73:11211127.

49. Bode-Böger, S.M., R.H. Böger, A. Creutzig, D. Tsikas, F.M. Gutzki, K Alexander, and J.C. Frölich. 1994. L-arginine infusion decreases peripheral arterial resistance and inhibits platelet aggregation in healthy subjects. Clin. Sci. (Lond.). 87:303-310.

50. Kanno, K., Y. Hirata, T. Emori, K. Ohta, S. Eguchi, T. Imai, and F. Marumo. 1992. L-arginine infusion induces hypotension and diuresis/natriuresis concomitant with increased urinary excretion of nitrite/nitrate and cyclic GMP in humans. Clin. Exp. Pharmacol. Physiol. 19:619-625.

51. Drexler, H., A.M. Zeiher, K. Meinzer, and H. Just. 1991. Correction of endothelial dysfunction in coronary microcirculation of hypercholesterolaemic patients by L-arginine. Lancet (N. Am. Ed.). 338:1546-1550.

52. Tsao, P. S., G. Theilmeier, S.H Singer, L.L.K. Leung, and J.P Cooke. 1994. L-arginine attenuates platelet reactivity in hypercholesterolemic rabbits. Arterioscler. Thromb. 14;1529-1533.

53. Kubes, P., M. Suzuki, and D.N. Ganger. 1991. Nitric oxide: an endogenous modulator of leukocyte adhesion. Proc. Natl. Acad. Sci. USA. 88:46514655 .

54. Tsao, P.S., L.M. McEvoy, H. Drexler, E.C. Butcher, and J.P. Cooke. 1994. Enhanced endothelial adhesiveness in hypercholesterolemia is attenuated by L-arginine. Circulation. 89:2176-2182.

55. Böger, R.H., S.M. Bode-Böger, and J.C. Frölich. 1996. The L-argininenitric oxide pathway. Role in atherosclerosis and therapeutic implications. Atherosclerosis. In press.

56. Myers, P.R., T.F. Wright, M.A. Tanner, and R.E. Ostlund, Jr. 1994. The effects of native and oxidized LDL on EDRF bioactivity and nitric oxide production in vascular endothelium. J. Lab. Clin. Med. 124:672-683.

57. Pohl, U., N. Heydari, and J. Galle. 1995. Effects of LDL on intracellular free calcium and nitric oxide-dependent cGMP formation in porcine endothelial cells. Atherosclerosis. 117:169-178.

58. Motani, A., L. Forster, S. Tull, E.E. Anggard, and G.A.A. Ferns. 1996 Insulin-like growth factor-I modulates monocyte adhesion to EAhy 926 endothelial cells. Int. J. Exp. Pathol. 77:31-35.

59. Mügge, A., R. Brandes, R.H. Böger, A. Dwenger, S.M. Bode-Böger, S. Kienke, J.C. Frölich, and P.R. Lichtlen. 1994. Vascular release of superoxide radicals is enhanced in hypercholesterolemic rabbits. J. Cardiovasc. Pharmacol. 24:994-998. 